\title{
THE EFFECT OF BITUMINOUS ADDITIVES ON THE
}

\section{CARBONIZATION OF OXIDIZED COALS}

\author{
M.F. Vega, A.M. Fernández, E. Díaz-Faes, M.D. Casal, C. Barriocanal* \\ Instituto Nacional del Carbón (INCAR-CSIC), Apdo 73, 33080 Oviedo. Spain
}

\begin{abstract}
Two bituminous coals of different rank and coking characteristics were oxidized at low temperature for two months. Bituminous additives obtained in-situ in the coking plant were used to improve the thermoplastic properties of the oxidized coals. The Gieseler fluidity test was applied to evaluate their coking properties. A thermogravimetric analysis (TGA) of the fresh, oxidized coals and their blends with the bituminous additives was carried in order to evaluate the interaction between the blend components. In addition, carbonization tests of the fresh and oxidized coals and the blends with the additives were carried out in a movable wall oven of $17 \mathrm{~kg}$ capacity and the quality of the cokes tested by means of standardized methods generally used by the steel industry. The additives increased coal fluidity but the original fluidity values could not be recovered. From TGA it was concluded that the blend components behave independently of one another during co-carbonization. The oxidation of coal leads to an increase in the dangerousness of the low volatile coal which was related to the porous texture of the cokes. In addition, it was found that the decrease in the quality of the coke produced from low rank oxidized coal can be partially recovered by using bituminous additives.
\end{abstract}

Keywords: Coal oxidation, additives, coke, coking pressure 


\section{1. Introduction}

The natural oxidation of coal (weathering) is a complex process involving several chemical processes, which are accompanied by physical changes $[1,2]$. Cokemaking is an important technological process that is adversely affected by coal oxidation [3]. This is directly reflected in a reduction in carbonization rate, coke yield, and coke quality [4-8], effects which reduce the productivity of the coke plant and undermine the economic feasibility of coke production. In the carbonization process the coal softens, melts and then resolidifies to form coke when heated in the absence of air. The fluid stage is very sensitive to the presence of oxidized coal because oxidation causes a decrease in the thermoplastic properties of coking coals. It is therefore necessary to develop efficient methods to restore the coking properties of oxidized coals in order to counteract the deleterious influence of oxidation on the coking process.

Many studies have been published on the modification of coal thermal decomposition by the use of additives. The effect of additives on the coking process includes modifications to the thermoplastic properties of the coal, the generation of coking pressure $[9,10]$ and a deterioration of the quality of the resultant cokes [11-13].

Several authors have studied the effect of aerial oxidation by using artificial oxidation as a model of coal weathering $[14,15]$ and have assessed the effect of different additives on the thermoplastic properties of oxidized coals. The results obtained vary depending on the type of additive used. For instance, the co-carbonization of oxidized coals with pitches and decacyclene can reduce the effects of mild oxidation. In this case the role of the additives is to replace the hydrogen lost during oxidation, which in turn influences coal fluidity $[16,17]$. The addition of small amounts of coal tar, diesel fuel and high-density polyethylene increases or preserves the fluid characteristics of 
weathered coals (as measured by rheometry), whereas the addition of sugar beet roots, bio-oil and lignin reduces coal fluidity [18].

In this work two bituminous coals of different rank were investigated in order to study the effect of mild oxidation on their coking properties and the effectiveness of adding carbonaceous additives as a means of restoring these properties without impairing the quality of the resulting cokes. The effect of the additives on coking pressure was also studied.

\section{Experimental}

\subsection{Materials}

Two coals of different rank were selected for the study, a high-volatile bituminous coal (HV) and a low-volatile bituminous coal (LV). Oxidation was performed in a drying chamber for two months in two ways: i) in trays (64 cm long, 40 $\mathrm{cm}$ wide and $3 \mathrm{~cm}$ high) where the coals were uniformly spread out in a thin layer in order to ensure that air exposure was similar for all the particles and ii) in baskets (48 $\mathrm{cm}$ high and $56 \mathrm{~cm}$ in diameter). Coal oxidized in trays and baskets will be labelled $\mathrm{O}$ and $\mathrm{OB}$, respectively, after their name. Representative samples were collected before the carbonization process for analysis. Two bituminous additives were used, a high temperature coal tar $(\mathrm{T})$ obtained as a by-product in the cokemaking industry and a coal tar sludge (CTS), a waste material extracted from the tar decanter of a by-products coking plant, made up of a blend of coal tar with coke fines from the coking ovens. To prepare the coal/additive blends, each bituminous additive was physically mixed with the corresponding coal in amounts of 2 wt. \%. The main characteristics of the pristine coals, oxidized coals and additives are shown in Table 1.

Proximate analyses were performed following the ISO562 and ISO1171 standard procedures for volatile matter and ash content, respectively. The elemental 
analysis was carried out using a LECO CHN-2000 device for C, H and N (ASTM D5773), a LECO S-144DR instrument (ASTM D-5016) for sulphur and a LECO VTF900 device for direct oxygen determination.

\subsection{Thermoplastic properties}

The thermoplastic properties of the fresh coals, oxidized coals and blends were assessed by means of the Gieseler test in a R.B. Automazione Gieseler plastometer PL 2000 following the ASTM D2639-08 standard procedure [19]. The characteristic temperatures in the development of coal fluidity i.e. softening temperature (Ts), maximum fluidity temperature (Tf) and resolidification temperature (Tr) were recorded together with the maximum fluidity value. The plastic/fluid range defined as the difference between the resolidification and softening temperatures was also recorded.

\subsection{Thermogravimetric analysis (TG/DTG)}

The TG/DTG analysis of the coals and coal/additives blends was carried out using a TA Instruments STD 2960 thermoanalyser. Samples $(10 \mathrm{mg})$ with a particle size of $<0.212$ mm were heated to $1000{ }^{\circ} \mathrm{C}$ at a rate of $3{ }^{\circ} \mathrm{C} / \mathrm{min}$ under a nitrogen flow of $100 \mathrm{ml} / \mathrm{min}$. From the data obtained by thermogravimetric analysis the volatile matter evolved up to specific temperatures (VMT) and the derivative weight loss curve (DTG curve) were calculated. The volatile matter evolved over a specific temperature range was calculated as the difference between the volatile matter evolved up to two specific temperatures (VMT1-VMT2). In addition, Tmax, the temperature of maximum volatile matter evolution was derived from the TG/DTG curves $[19,20]$. The precision in the measurement of the DTGmax value is $\pm 0.02 \% / \mathrm{min}$.

\subsection{Carbonization test}

Carbonization tests were carried out in a movable wall oven of approximately $17 \mathrm{Kg}$ capacity (MWO17). The dimensions of the oven are $250 \mathrm{~mm} L$ x $165 \mathrm{~mm} W \times 790 \mathrm{~mm}$ 
$H$. A load cell was mounted on the movable wall to measure the force exerted on the wall during carbonization. A programmable controller was used to control the oven temperature. The temperature at the centre of the coal charge was monitored by means of a thermocouple connected to a computer. The coal was charged when the oven walls reached $1100{ }^{\circ} \mathrm{C}$. The temperature of the wall was kept constant throughout the test. The coke was pushed after $3 \mathrm{~h}$ and $30 \mathrm{~min}$ [21]. As bulk density varies as a function of grain size and moisture content, both parameters were kept as close as possible in each series of carbonizations to give mean values of 791 and $771 \mathrm{~kg} / \mathrm{m}^{3}$ for $\mathrm{LV}$ and $\mathrm{HV}$ respectively.

\subsection{Semicoke contraction}

The Koppers-INCAR test was used to assess the variation in charge height during heating. A coal sample of $80 \mathrm{~g}$ was heated from the sole in a stainless steel crucible for two hours. The change in charge height compared to the initial state of the coal sample was recorded on a graph and expressed in mm. Contraction is expressed by negative values, while positive values indicate expansion.

\subsection{Textural characterization}

Rectangular prism pieces of semicokes produced at $575{ }^{\circ} \mathrm{C}$ with the following sizes: a height of $10 \mathrm{~mm}$, a width of $5 \mathrm{~mm}$ and a length of $8 \mathrm{~mm}$, were used for the textural characterization. The pore size distribution was determined on a Micromeritics autopore IV 9500 mercury porosimeter by increasing the pressure up to $227 \mathrm{MPa}$ in order to determine pore sizes in the range between $140 \mu \mathrm{m}$ to $5.5 \mathrm{~nm}$. Porosity was grouped into three categories: coarse porosity $(\mathrm{dp}>12 \mu \mathrm{m})$, macroporosity $(12 \mu \mathrm{m}>\mathrm{dp}>50 \mathrm{~nm})$ and mesoporosity $(50 \mathrm{~nm}>\mathrm{dp}>5.5 \mathrm{~nm})$.

FE-SEM images were obtained on a Quanta FEG650 microscope (FEI Company) at 25 $\mathrm{kV}$. 


\subsection{Coke quality}

The cold mechanical strength of the cokes produced was assessed by applying the JIS test (JIS K2151 standard procedure). After the test the coke was sieved and the DI150/15 and D150/5 indices were calculated from the amount of coke with a particle size greater than $15 \mathrm{~mm}$ and smaller than $5 \mathrm{~mm}$ respectively. Coke reactivity and mechanical strength after reaction were assessed by means of the NSC test (ASTM D5341 standard procedure). A coke destined for use in blast furnaces must have a CRI index value in the $20-30 \%$ range and a CSR index value of above $60-65 \%$ [22].

\section{Results and discussion}

The fresh coals were oxidized and then different additives were used to restore the properties of the oxidized coals to their original state. The main characteristics of the fresh and oxidized coals together with those of the bituminous additives are shown in Table 1 . The effect of the oxidation on the proximate and ultimate analyses is slightly more noticeable in the high volatile coal than in the low volatile one. In relation to oxidation, the proximate analyses reveal an increase in ash content for both coals but a reduction in VM content only in HV (Table 1). These trends are accompanied by a very slight decline in elemental carbon, elemental hydrogen and sulphur content and a slight increase in oxygen content, confirming the findings of a previous study [23].

\subsection{Recovery of coal thermoplastic properties with the use of additives}

To study the thermoplastic properties of the coals, a Gieseler plastometer was used. This method is employed in the steel industry and is considered to be a very sensitive indicator of the degree of oxidation in coals.

The plastic properties of the fresh and oxidized coals and their blends with the additives, $\mathrm{T}$ and CTS, are shown in Table 2. In accordance with its rank, the low volatile coal has higher temperature of maximum fluidity, a lower maximum fluidity and a narrower plastic range. 
The variation in fluidity with rank is associated with the variation in coal structure with rank. In low-rank coals the presence of oxygen prevents fusion. With an increase in rank the oxygen content decreases and the $\mathrm{O}$ bonds change to $\mathrm{H}$ bonds that are more labile and allow the fusion of coal when it is heated. However, any additional increase in rank entails a greater degree of aromaticity and the presence of covalent bonds that cause coal fluidity to decrease again $[3,24]$.

A comparison of the fresh and oxidized coals reveals a change in plasticity behaviour, with the depletion of MF and a decrease in the plastic range (Table 2). The decrease in Gieseler plasticity is more noticeable in the coals oxidized in the tray: the loss of MF compared to that of the fresh coal, is $80 \%$ for LVO, and $67 \%$ for LVOB. The impairment effect that oxidation has on coal plasticity and therefore on coking properties, is well known [5-8]. Due to the introduction of oxygen-bearing functional groups into the macromolecular structure of the coal there is an increase in cross-link density that inhibits plasticity during the carbonization process [25-27]. In addition, there is a loss of donatable hydrogen species due to oxidation, which contributes to the generation of fluidity $[2,14]$.

To recover the plastic properties of the coal, and improve the quality of the resulting coke, 2 wt. \% of two different additives, T and CTS, were added to the oxidized coals. These additives may be able to produce an increase in coal plasticity because the polycondensed aromatic compounds formed during their pyrolysis provide a pathway for hydrogen transfer reactions that stabilize radicals resulting from coal decomposition $[21,28]$.

The addition of 2 wt. \% of cokemaking by-products is based on previous research [21] that showed that the presence of small amounts of certain wastes in coking mixtures does not adversely affect coke quality. 
The addition of $\mathrm{T}$ to coal LV produced a $40 \%$ increase in fluidity, whereas the use of CTS did not produce any appreciable variation. In the case of the blends with coal HV plasticity was not observed to vary, because, due to the high fluidity of coal $\mathrm{HV}$, it lies outside the range of detection of the plastometer. In the case of the very high plasticity coals, therefore, the test did not reveal the effect of additives on coal plasticity because the expected plasticity of HV2T and HV2CTS was outside the experimental range of the equipment.

The effect of tray-oxidation (LVO an HVO) was more pronounced that basketoxidation (LVOB and HVOB) because a greater amount of coal surface was in contact with air (Table 2). The LVO and HVO samples therefore were chosen to study the influence of the additives. It was found that, although both additives enhance the thermoplastic properties of coal, the MF of the blends does not regain the plasticity of the fresh coal. The increase in Gieseler MF due to the additive is more pronounced in the HV coal than in the LV coal (181\% vs. $154 \%$ in the case of T and $70 \%$ vs. $13 \%$ in the case of CTS). Furthermore, the effect of $\mathrm{T}$ is greater than that of CTS. The coal tar sludge (CTS) is a complex liquid mixture of organic components and contains a high proportion of solid particles. The composition of the $\mathrm{T}$ and CTS additives is very similar, the main difference being the greater amount of inert compounds in CTS. The larger amount of inert matter in the coal tar sludge is also confirmed by the higher amount of ash content (Table 1). The same product was tested in a previous paper [28]. In that case an insoluble fraction in $\mathrm{CS}_{2}$ of more than $20 \%$ was obtained in CTS. The insoluble fraction in $\mathrm{CS}_{2}$ is a poor-caking filler component that plays an important role in thermoplastic behaviour. Inert matter does not pass through a plastic stage. Moreover, a large part of this material has a porous surface that absorbs the decomposition products from coal, which otherwise could act as plasticizers $[3,29,30]$. Its presence in 
the reacting media therefore has a negative influence on the development of coal plasticity.

\subsection{Thermogravimetric analysis}

The DTG curves corresponding to the additives, the fresh coals and the oxidized coals are shown in Figure 1. Table 3 summarizes the most relevant parameters derived from this analysis for the fresh and oxidized coals, additives and blends studied.

It can be observed that coals behave in accordance with their rank [20]. In the lowest volatile coal (LV) the evolution of volatile matter is slower and takes place at a higher temperature. This is reflected in the displacement to higher values of the temperatures at which weight loss begins and ends and a similar displacement of the temperature of maximum volatiles release (Table 3 ). The distribution of the volatile matter released at different stages of the pyrolysis process also varies with rank. Therefore, the LV coal, a coal with low plasticity, produces more volatile matter in the post-plastic range between 500 and $750{ }^{\circ} \mathrm{C}$. In addition, the amount of volatile matter released by the $\mathrm{HV}$ coal, the highest fluidity coal, during the pre-plastic $\left(400{ }^{\circ} \mathrm{C}\right)$ and the plastic stage $\left(400-500{ }^{\circ} \mathrm{C}\right)$, is greater than that released by the high rank coal. This behaviour is due to the macromolecular structure of the low-volatile coal that contains a smaller proportion of thermally-labile groups than the high-volatile bituminous coal.

In the case of the oxidized coals (Table 3), it can be seen that the evolution of volatile matter occurs at a slower rate than in the fresh coal. Thermal degradation begins at a lower temperature and extends over a wider temperature range. In addition, the percentage of $\mathrm{VM}$ released in the low temperature range, up to $400{ }^{\circ} \mathrm{C}$, increases. The weight loss at this temperature is attributed to light species. It can therefore be inferred that, as a result of oxidation, functional groups which can be easily broken up are generated in the coal structure. 
The main pyrolysis reactions occur and the plastic stage takes place between 400 and $500{ }^{\circ} \mathrm{C}$. Due to oxidation, there is a slight decrease in the release of VM in this intermediate temperature range. The reduction in the number of aliphatic groups, a key factor in the development of fluidity, may explain not only the decrease in VM release but also the reduction in fluidity [31]. The TG profiles of the two additives are very similar although some differences can be appreciated (Figure 1). CTS generates a lower amount of volatile matter compounds than $\mathrm{T}$, in agreement with the proximate analysis presented in Table 1. Both bituminous materials release most of their volatile matter below $400{ }^{\circ} \mathrm{C}$, and only a small amount is lost above this temperature (Table 3). It can also be observed that the decomposition profiles of the additives are different from those of the coals. The mass loss of the additives occurs in a series of complex steps and they decompose in a shorter temperature interval i.e. between 356 and $329{ }^{\circ} \mathrm{C}$ for $\mathrm{T}$ and CTS respectively while, in the case of the coals, the interval extends beyond $450{ }^{\circ} \mathrm{C}$ (Figure 1, Table 3). The thermal degradation of the additives starts at temperatures below that of the coals (around $130{ }^{\circ} \mathrm{C}$ ) and finishes at temperatures close to the softening temperature of coal (about $470{ }^{\circ} \mathrm{C}$, Table 3). The temperature of maximum VM release (Tmax) is approximately $250{ }^{\circ} \mathrm{C}$ lower than the Tmax of both coals.

The differences between the thermogravimetric curves of the oxidized coals and the oxidized coal/additives blends are mainly reflected in the decomposition of the blends which begins at a lower temperature and an increase in volatile matter evolved up to $400{ }^{\circ} \mathrm{C}$ (Table 3$)$.

In order to investigate the synergistic effect between the additives and the coals, the differences between the values of the experimental and estimated loss mass $(\Delta W)$ in the course of pyrolysis, expressed as percentage, have been defined as:

$\Delta \mathrm{W}=\mathrm{W}_{\exp }-\left(0.98 \mathrm{~W}_{1}+0.02 \mathrm{~W}_{2}\right)$ 
where $\mathrm{W}_{\text {exp }}$ is the weight loss of the blend, 0.98 is the weight fraction of oxidized coal in the blend, 0.02 is the weight fraction of the additives (T and CTS) present in the blend and $\mathrm{W}_{\mathrm{i}}$ is the experimental weight loss of the oxidized coal or additive (T or CTS) under the same operational conditions.

Figure $\mathrm{S} 1$, shows the variation in $\Delta \mathrm{W}$ with temperature for the oxidized coal/additive mixtures. For all the blends studied the variation in $\Delta \mathrm{W}$ is negligible (lower than $\pm 1 \%$ ). Therefore, no apparent synergism exists between the coal and the additive.

It is known that there is a relationship between the volatile matter evolved in the temperature range of 400 and $500{ }^{\circ} \mathrm{C}$-the period from the beginning to the end of the coal plastic stage- and the maximum fluidity of a coal [20]. Figure 2 shows the variation in VM400-500 with the Gieseler MF, expressed as log base 10, for fresh and oxidized coals and blends of the coals oxidized in a tray with different additives ( $T$ and CTS). An increase in Gieseler fluidity corresponds to an increase in the amount of VM released between 400 and $500{ }^{\circ} \mathrm{C}$. As mentioned above, high volatile bituminous coals release more VM between $400-500{ }^{\circ} \mathrm{C}$ and exhibit a higher fluidity according to their rank. In addition, oxidized coals lose plasticity and release a smaller amount of VM.

Previous research carried out on the additives T and CTS has shown that, although these cokemaking by-products lose most of their VM below $400{ }^{\circ} \mathrm{C}$, volatiles significantly affect the formation of the plastic stage $[28,32]$. In this case, the volatiles appear to have a solubilising effect on the coal, giving rise to an increase in the plastic range and maximum fluidity. Furthermore, the volatiles evolved in the coal plastic range contribute to stabilizing the radicals formed during coal decomposition, providing pathways for $\mathrm{H}$ transfer reactions due to the presence of highly polycondensed aromatic species. In the case of the oxidized coal LV, the presence of CTS reduces the amount of VM released between $400-500{ }^{\circ} \mathrm{C}$ and the increase in coal fluidity is not as high as for 
LVO2T. Although HVO2T and HVO2CTS have a similar amount of VM400-500 release, the increase in plasticity is higher when $\mathrm{T}$ is present in the blend. When $\mathrm{T}$ is added to the coal, the aromatic hydrocarbons evolved during the pyrolysis of $\mathrm{T}$ are compatible with products liberated during coal decomposition. The amount of hydrogen from aromatization reactions increases, contributing to the stabilization of free radicals arising from pyrolysis reactions. As a result, there is an increase in coal fluidity during the coking process. With regard to the CTS additive, it is necessary to take into account the presence of inert compounds, which have a negative effect on coal plasticity. Hence, two opposed influences are present during the co-pyrolysis of CTS and the coal, one of which contributes to the increase in coal plasticity and the other to its reduction. For this reason the gain in plasticity of the oxidized coal/CTS mixtures is not as high as in the case of $\mathrm{T}$.

\subsection{Coking Pressure and semicoke contraction}

Table 4 shows the coking pressure and expansion/contraction data corresponding to the fresh and oxidized coals and the blends of oxidized coal with the additives. If the coking pressure measured in the MWO17 is higher than $15 \mathrm{kPa}$ [33], the coals are considered to be dangerous. The criterion used in the Koppers-INCAR test considers that coals with a contraction greater than $10 \mathrm{~mm}$ are not dangerous [34]. Therefore, a high coking pressure is associated with low contraction values.

According to these criteria, LV is a dangerous coal, whereas HV is a safe coal. It is known that coking pressure depends on the nature of the coal. Generally, high volatile bituminous coals are fluid coals which do not cause excessive swelling in the plastic stage. This is due to the fact that volatile material is not retained as readily as in the case of dangerous coals. However, low volatile coals are low plasticity coals with a less permeable layer for volatile matter and therefore they develop a higher coking pressure. 
The effect of oxidation on the development of coking pressure is different for the two coals. The LV coal becomes more dangerous as it develops a higher coking pressure and undergoes a lower Koppers contraction, whereas the HV coal remains safe (Table 4). Due to the presence of oxygen in the low volatile bituminous coal, the fluidity and fluid range decrease with oxidation, resulting in a thinner and more viscous plastic stage that can make the passage of volatiles difficult. Hence pressure builds up and contraction decreases [35]. On the other hand, oxidation has a minimal effect on the coking pressure of the high fluidity coal, HV. This may be due to the nature of the coke structure formed during the carbonization of safe coals that offers an easily accessible escape route for volatile matter.

As mentioned earlier, coal oxidized in a tray is more affected by oxidation than coal oxidized in a basket. This is reflected in a slight increase in coking pressure and a decrease in Koppers contraction for tray-oxidized coal. For this reason, tray-oxidized coals were chosen to be mixed with the two additives for the co-carbonization tests.

In the case of the dangerous coal, the addition of T and CTS causes a build-up in the coking pressure. In particular, the addition of coal tar had a stronger effect on the increase in coking pressure (Table 4). However, with CTS the presence of inert material again needs to be taken into account. The addition of inert material to a coal causes a decrease in coking pressure which can be attributed to an increase of the permeability of the plastic layer [36]. It is for this reason that the increase in coking pressure in the LVO2CTS blend is not as high as with coal tar. The effect of coal tar on the coking pressure is greater than the effect of the CTS and therefore, in the case of the nondangerous coal $\mathrm{HV}$, only the HVO2T blend is carbonized. The results in Table 4 indicate that the use of $\mathrm{T}$ does not affect the generation of coking pressure at all in the case of the high volatile, non-dangerous coal HV. 
According to results of previous research works, the maximum pressure developed during the coking process appears at a temperature close to the resolidification temperature, as measured by a Gieseler plastometer and to the temperature where the maximum rate of gas evolution occurs [37,38]. Figure 3 shows the coking pressure and the Koppers contraction developed by the coals and the blends tested, plotted against the difference between the resolidification temperature as recorded by the Gieseler test $(\mathrm{Tr})$ and the temperature of maximum rate of volatiles release (Tmax). In general, the Tr-Tmax falls to lower values as the dangerousness of the coals/blends increases. Thus, the oxidized coal -LVO- and oxidized coal/additives blends - LVO2CTS and LVO2T- whose resolidification temperature is close to that of the maximum emission of volatiles, develop minor contractions and a higher coking pressure than the fresh coal-LV-. In the literature, $[39,40]$ it has been demonstrated that the low permeability zone occurs during the plastic range in safe coals, while the low permeability zone is associated with a temperature higher than that of resolidification in the case of dangerous coals. In agreement with this finding, in dangerous coal/blends the volatile matter is released closer to the resolidification temperature. This is a low permeability area, implying that it will be more difficult for gases to find a way of escape.

Previous research $[37,41,42]$ has shown that the porous texture of recently solidified semicokes is useful for studying differences in coals that developed different coking pressures during carbonization. This is because the most important processes affecting coke porous texture occur during the plastic stage. The relation between semicoke pore structure and coking pressure will be reflected in differences in the pore size distribution of coals which generate different coking pressures. Therefore, mercury intrusion curves were used to illustrate the pore size distribution of the semicokes 
(Figure 4). The volume of pores larger than $12 \mu \mathrm{m}$, macro-pores $(12 \mu \mathrm{m}<$ pore size $<$ $50 \mathrm{~nm})$, meso-pores $(50 \mathrm{~nm}<$ pore size $<5.6 \mathrm{~nm})$ and micro-pores (pore size $<5.6 \mathrm{~nm}$ ) was calculated for semicokes produced at $575{ }^{\circ} \mathrm{C}$. The results show that both the total open pore volume and open porosity remain almost unchanged (around 50\% and 513 $\mathrm{mm}^{3} / \mathrm{g}$ respectively), for the oxidized coal and for the blends with the additives $\mathrm{T}$ and CTS.

Cokes used in the cokemaking process are macro-porous materials. This is why for all the samples tested, volume is mostly dominated by macro-pores with diameters between $12 \mu \mathrm{m}$ and $50 \mathrm{~nm}$ followed by pores larger than $12 \mu \mathrm{m}$, with only a minor contribution from small-range pores (Figure 4). Coal oxidation produces a decrease in pore volumes larger than $12 \mu \mathrm{m}$, but an increase in pore volumes from $12 \mu \mathrm{m}$ to $50 \mathrm{~nm}$.

The presence of additives in the blend causes changes in the pore structure. The addition of coal tar to the oxidized coal reduces the volume of coarse pores $(>12 \mu \mathrm{m})$, but increases the macro-pore volumes. On the other hand, the addition of CTS to the blend, hardly changes the coarse-pore and macro-pore distributions in the coke structure of the blend when compared to the pore distribution in coke derived from the oxidized coal. This is confirmed by the SEM images in Figure 5. The results indicate that semicoke from fresh coal has pores with a larger diameter compared to those of the oxidized coal and the blends. In addition the LVO2T blend has the highest macro-pore volume, as can be seen in the enlarged image in Figure 5e.

To study the relationship between the porous structure of the semicoke and coking pressure, the variation of the coarse pores and macro-pores with coking pressure and Koppers contraction has been plotted in Figure 6. Here it can be seen that the development of a high coking pressure is associated with a larger volume of $>12 \mu \mathrm{m}$ pores and a smaller volume of pores between $12 \mu \mathrm{m}$ and $50 \mathrm{~nm}$ (Figure 6). 
The differences in the amounts of coarse and macropores between the samples tested is related to the process of pore formation, particularly in the case of macro pores. Pore formation starts just below the softening point. During this stage, a solid-liquidgaseous mixture is present. The volatile matter in the mixture forms bubbles, which due to the high viscosity of the surrounding material, find it difficult to move. The bubbles grow due to the influx of volatiles from the plastic coal or due to coalescence with other bubbles. After the plastic stage has come to an end, the equilibrium between the bubbles and the surrounding material breaks down, the trapped volatile matter is liberated and pores appear.

Coal oxidation produces a decrease in coal fluidity and in permeability during the plastic stage. As a result it is more difficult for gases to escape and for bubbles to coalesce and expand. Also the amount of pores larger than $12 \mu \mathrm{m}$ decreases, whereas the number of macropores increases.

Blockage of the pores by condensed tar may lead to a decrease in the number of coarse pores, significantly reducing permeability and increasing coking pressure. The behaviour of heavy compounds originating from the decomposition products present in the plastic stage may also have an influence on the development of coking pressure. Dangerous coals are dominated by the presence of heavy compounds that struggle to pass through the different layers coexisting in the coking process [24]. If these highmolecular weight components condense, they may occupy the large pores of the semicoke layer, plug the pores and reduce gas permeability. SEM images reveal that in the LVO2T blend there is a greater number of clogged pores (Figure 5f). Interestingly this sample has the smallest volume of pores larger than $12 \mu \mathrm{m}$ but it develops the highest coking pressure. 
The LVO2CTS blend shows a more similar porous structure to that of the oxidized coal, LVO, than to that of the LVO2T blend. This may be due to the inert material present in the CTS additive. Inert material may absorb some of the decomposition products, thereby reducing the presence of heavier compounds in the oxidized coal/additive blend and the possibility of pore blockage. As a result the coking pressure decreases.

A coke destined for use in the blast furnace must be of the highest quality. In this study, coke quality was assessed in terms of cold mechanical strength (JIS indices), reactivity to $\mathrm{CO}_{2}(\mathrm{CRI})$ and mechanical strength after reaction (CSR) (Table 5). Due to the difference in rank, the CSR of the LV coal is higher than that of HV. In the case of LV oxidation both in the baskets and the trays produces no modification of the CSR although some decrease is observed in the DI150/15 (around 5 points). The use of additives with the oxidized LV coal does not produce any significant change in the CSR value (1 point) but causes a 3-point increase in the JIS DI150/15 index. The effect is greater in the $\mathrm{HV}$ coal especially in relation to the tray-oxidized coal where there is a reduction of 8 points in the CSR and 7 points in the DI150/15 index. However, cocarbonization with the additive results in a recovery of 4 points in the CSR value.

Coal oxidation and the addition of the two different carbonaceous materials to the oxidized coals significantly affect their thermoplastic behavior. Yet the effect on coke quality is different for each coal. While the quality of the coke prepared with LV is not affected either by oxidation or the additives, with HV oxidation there is a decrease in the quality of the coke which is only partially recovered by the use of a bituminous additive.

\section{Conclusions}


The use of bituminous additives obtained in-situ in the coking plants contributed to the recovery of the thermoplastic properties of slightly oxidized coals. Although lowtemperature oxidation undermined the thermoplastic properties of the coals used in this study, the effect was not reflected in a serious impairment of the quality of the resultant coke, especially in the case of the high-rank coal which after 60 days of oxidation still maintained the same value of coke strength after reaction (CSR) as when it was first carbonized. The most important effect of using additives was to increase the coking pressure in the case of the low volatile matter content coal, rendering it more dangerous than when it was carbonized fresh and after oxidation. The use of the additives also led to a higher coking pressure, especially in the case of the coal tar. A direct relationship was observed between the macropore volume of the semicokes produced at $575^{\circ} \mathrm{C}$ and the coking pressure generated during the process.

\section{Acknowledgments}

The research leading to these results has received funding from the European Union's Research Programme of the Research Fund for Coal and Steel (RFCS) research programme under grant agreement No. RFCR-CT-2013-00007. 
[1] C. R. Nelson, Chemistry of coal weathering, Coal Science and Technology, Elsevier, Amsterdam, 1989.

[2] S.V. Pisupati, A.W. Scaroni, Natural weathering and laboratory oxidation of bituminous coals: Organic and inorganic structural changes, Fuel 72 (1993) 531542.

[3] R. Loison, P. Foch, A. Boyer, Coke: Quality and Production, Elsevier, London, 1989.

[4] J.W. Larsen, D. Lee, T. Schmidt, A. Grint, Multiple mechanisms for the loss of coking properties caused by mild air oxidation, Fuel 65 (1986) 595-596.

[5] J.J. Pis, A. Cagigas, P. Simón, J.J. Lorenzana, Effect of aerial oxidation of coking coals on the technological properties of the resulting cokes, Fuel Process. Technol. 20 (1988) 307-316.

[6] Valia, H.S., Effects of coal oxidation on coke making, in: ISS-Ironmak. Conf. Proc, Iron And Steel Society, Detroit, 1990, 199-209.

[7] H. Seki, O. Ito, M. Iino, Effect of mild oxidation of bituminous coals on caking properties, Fuel 69 (1990) 317-321.

[8] M.D. Casal, A.I. González, C.S. Canga, C. Barriocanal, J.J. Pis, R. Alvarez, M.A. Díez, Modifications of coking coal and metallurgical coke properties induced by coal weathering, Fuel Process. Technol. 84 (2003) 47-62.

[9] A.M. Fernández, C. Barriocanal, M.A. Díez, R. Alvarez, Evaluation of bituminous wastes as coal fluidity enhancers, Fuel 101 (2012) 45-52.

[10] M.A. Díez, R. Alvarez, S. Melendi, C. Barriocanal, Feedstock recycling of plastic wastes/oil mixtures in cokemaking, Fuel 88 (2009) 1937-1944.

[11] V.N. Shevkoplyas, Coal carbonization with addition of hydrochloric acid as a way of improving coke quality, Fuel 81 (2002) 947-950.

[12] A.M. Fernández, C. Barriocanal, R. Alvarez, The effect of additives on coking pressure and coke quality, Fuel 95 (2012) 642-647.

[13] V.M. Gulyaev, V.D. Barskii, A.G. Rudnitskii, Coke quality on adding coking byproducts to the batch, Coke Chem. 54 (2011) 147-156. 
[14] M.M. Wu, G.A. Robbins, R.A. Winschel, F.P. Burke, Low-temperature coal weathering: its chemical nature and effects on coal properties, Energy Fuels 2 (1988) 150-157.

[15] H. Wang, B.Z. Dlugogorski, E.M. Kennedy, Coal oxidation at low temperatures: Oxygen consumption, oxidation products, reaction mechanism and kinetic modelling, Prog. Energy Combust. Sci. 29 (2003) 487-513.

[16] A.H. Clemens, T.W. Matheson, The effect of decacyclene on coal fluidity, Fuel 66 (1987) 1009-1010.

[17] Z. Qian, H. Marsh, The co-carbonization of oxidized coals with pitches and decacyclene, Fuel 63 (1984) 1588-1593.

[18] M. Castro-Díaz, M.F. Vega, C. Barriocanal, C.E. Snape, Utilization of Carbonaceous Materials to Restore the Coking Properties of Weathered Coals, Energy Fuels 29 (2015) 5744-5749.

[19] E. Díaz-Faes, C. Barriocanal, M.A. Díez, R. Alvarez, Characterization of different origin coking coals and their blends by Gieseler plasticity and TGA, J. Anal. Appl. Pyrolysis. 80 (2007) 203-208.

[20] C. Barriocanal, M.A. Díez, R. Alvarez, M.D. Casal, C.S. Canga, On the relationship between coal plasticity and thermogravimetric analysis, J. Anal. Appl. Pyrolysis 67 (2003) 23-40.

[21] A.M. Fernández, C. Barriocanal, E. Díaz-Faes, Recycling tyre wastes as additives in industrial coal blends for cokemaking, Fuel Process. Technol. 132 (2015) 173-179

[22] R. Alvarez, M.A. Díez, C. Barriocanal, E. Díaz-Faes, J.L.G. Cimadevilla, An approach to blast furnace coke quality prediction 86 (2007) 2159-2166.

[23] S.L. Bend, I.A.S. Edwards, H. Marsh, The effects of oxidation and weathering on coal combustion, ACS Division of Fuel Chemistry preprints 34 (1989) 923930.

[24] M.D. Casal, M.A. Díez, R. Alvarez, C. Barriocanal, Suitability of Gray-King pyrolysis to evaluate coking pressure, J. Anal. Appl. Pyrolysis 79 (2007) 161168. 
[25] P.C. Painter, R.W. Snyder, D.E. Pearson, J. Kwong, Fourier transform infrared study of the variation in the oxidation of a coking coal, Fuel 59 (1980) 282286.

[26] R. Liotta, G. Brons, J. Isaacs, Oxidative weathering of Illinois No.6 coal, Fuel 62 (1983) 781-791.

[27] M. Krzesińska, B. Pilawa, S. Pusz, The physical parameters of different rank coals related to their degree of cross-linking and the caking ability, Energy Fuels, 20 (2006) 1103-1110.

[28] M.A. Diez, A. Domínguez, C. Barriocanal, R. Alvarez, C.G. Blanco, M.D. Casal, C.S. Canga, Gas chromatographic study for the evaluation of the suitability of bituminous waste material as an additive for coke production, J. Chromatogr. A. 823 (1998) 527-536.

[29] A.M. Fernández, C. Barriocanal, M.A. Díez, R. Alvarez, Importance of the textural characteristics of inert additives in the reduction of coal thermoplastic properties, Fuel 89 (2010) 3388-3392.

[30] M. Krzesińska, U. Szeluga, Ł. Smędowski, J. Majewska, S. Pusz, S. Czajkowska, B. Kwiecińska, TGA and DMA studies of blends from very good coking Zofiówka coal and various carbon additives: Weakly coking coals, industrial coke and carbonized plants, Int. J. Coal Geol., 81 (2010) 293-300.

[31] G. De La Puente, M.J. Iglesias, E. Fuente, J.J. Pis, Changes in the structure of coals of different rank due to oxidation - Effects on pyrolysis behaviour, J. Anal. Appl. Pyrolysis. 47 (1998) 33-42.

[32] C. Barriocanal, R. Alvarez, C.S. Canga, M.A. Díez, On the possibility of using coking plant waste materials as additives for coke production, Energy Fuels 12 (1998) 981-989.

[33] E. Díaz-Faes, Study at different scales of coking pressure and coke quality of coking coals, Universidad de Oviedo, 2010.

[34] J. Escudero, R. Alvarez, Influence of air oxidation on the pressure exerted by coking coals during carbonization, Fuel 60 (1981) 251-253.

[35] K.M. Steel, M.C. Diaz, J.J. Duffy, C.E. Snape, M.R. Mahoney, Influence of thermoplastic properties on coking pressure generation: Part IV - Further 
evidence of the role of bubble coalescence in the mechanism for pressure generation, Fuel 129 (2014) 102-110.

[36] S. Nomura, M. Mahoney, K. Fukuda, K. Kato, A.L. Bas, S. McGuire, The mechanism of coking pressure generation I: Effect of high volatile matter coking coal, semi-anthracite and coke breeze on coking pressure and plastic coal layer permeability, Fuel 89 (2010) 1549-1556.

[37] S. Nomura, K.M. Thomas, Some aspects of the generation of coking pressure during coal carbonization, Fuel 75 (1996) 801-808.

[38] C. Barriocanal, J.W. Patrick, A. Walker, The laboratory identification of dangerously coking coals, Fuel 77 (1998) 881-884.

[39] A. Koch, R. Gruber, D. Cagniant, J.M. Duchène, A physicochemical study of carbonization phases, Part II: Quenching experiments at the pilot scale, Fuel Process. Technol. 48 (1996) 29-37.

[40] M.D. Casal, E. Díaz-Faes, R. Alvarez, M.A. Díez, C. Barriocanal, Influence of the permeability of the coal plastic layer on coking pressure, Fuel. 85 (2006) 281-288.

[41] M.D. Casal, C. Barriocanal, M.A. Díez, R. Alvarez, Influence of porosity and fissuring on coking pressure generation, Fuel. 87 (2008) 2437-2443.

[42] D. Hays, J.W. Patrick, A. Walker, Pore structure development during coal carbonization. 1. Behaviour of single coals, Fuel. 55 (1976) 297-302. 
Table 1. Proximate and ultimate analyses of the fresh coals (LV, HV), the oxidized coals in baskets (LVOB, HVOB) and trays (LVO, HVO), coal tar (T) and coal tar sludge (CTS).

\begin{tabular}{|c|c|c|c|c|c|c|c|c|}
\hline Coals & LV & LVOB & LVO & HV & HVOB & HVO & $\mathrm{T}$ & CTS \\
\hline Ash (wt.\% db $\left.{ }^{a}\right)$ & 8.5 & 9.2 & 9.2 & 7.0 & 7.6 & 9.8 & 0.8 & 2.2 \\
\hline $\mathrm{VM}^{\mathrm{b}}\left(\mathrm{wt} . \% \mathrm{db}^{\mathrm{a}}\right)$ & 20.3 & 20.6 & 20.1 & 34.2 & 30.6 & 30.5 & 61.9 & 44.9 \\
\hline $\mathrm{C}\left(\mathrm{wt} . \% \mathrm{db}^{\mathrm{a}}\right)$ & 81.7 & 80.8 & 80.9 & 80.8 & 80.3 & 77.9 & 90.3 & 89.1 \\
\hline $\mathrm{H}\left(\mathrm{wt} . \% \mathrm{db}^{\mathrm{a}}\right)$ & 4.3 & 4.4 & 4.3 & 5.1 & 5.0 & 4.8 & 4.7 & 4.2 \\
\hline $\mathrm{N}\left(\right.$ wt. $\left.\% \mathrm{db}^{\mathrm{a}}\right)$ & 1.8 & 1.8 & 1.8 & 1.8 & 1.7 & 1.7 & 0.8 & 1.1 \\
\hline $\mathrm{S}\left(\mathrm{wt} . \% \mathrm{db}^{\mathrm{a}}\right)$ & 0.71 & 0.73 & 0.66 & 0.98 & 0.83 & 0.88 & 0.38 & 0.52 \\
\hline $\mathrm{O}\left(\mathrm{wt} . \% \mathrm{db}^{\mathrm{a}}\right)$ & 2.8 & 3.5 & 3.9 & 4.3 & 5.0 & 4.8 & 2.8 & 1.9 \\
\hline $\mathrm{C} / \mathrm{O}^{\mathrm{c}}$ & 39 & 31 & 37 & 25 & 22 & 22 & 43 & 61 \\
\hline
\end{tabular}

${ }^{\mathrm{a}}$ Dry basis.

${ }^{\mathrm{b}}$ Volatile matter.

${ }^{\mathrm{c}}$ Atomic ratio. 
Table 2. Thermoplastic parameters of fresh and oxidized coals and their blends with 2 wt. $\%$ of additives.

\begin{tabular}{lccccc}
\hline & ${\operatorname{Ts~}\left({ }^{\circ} \mathrm{C}\right)^{\mathrm{a}}}$ & $\mathrm{Tf}\left({ }^{\circ} \mathrm{C}\right)^{\mathrm{b}}$ & $\operatorname{Tr}\left({ }^{\circ} \mathrm{C}\right)^{\mathrm{c}}$ & $\mathrm{Tr}-\mathrm{Ts}\left({ }^{\circ} \mathrm{C}\right)^{\mathrm{d}}$ & $\mathrm{MF}(\mathrm{ddpm})^{\mathrm{e}}$ \\
\hline LV & 416 & 467 & 507 & 91 & 519 \\
LV2T & 410 & 467 & 502 & 92 & 725 \\
LV2CTS & 408 & 468 & 504 & 96 & 518 \\
LVOB & 419 & 473 & 506 & 87 & 167 \\
LVO & 425 & 470 & 503 & 78 & 99 \\
LVO2T & 414 & 471 & 504 & 90 & 251 \\
LVO2CTS & 418 & 467 & 502 & 84 & 112 \\
\hline HV & 381 & 441 & 486 & 105 & 28322 \\
HV2T & 380 & 446 & 488 & 108 & 28048 \\
HV2CTS & 380 & 446 & 488 & 108 & 28242 \\
HVOB & 389 & 447 & 489 & 100 & 10919 \\
HVO & 387 & 443 & 486 & 99 & 8934 \\
HVO2T & 385 & 445 & 490 & 105 & 25072 \\
HVO2CTS & 387 & 444 & 489 & 102 & 15158 \\
\hline
\end{tabular}

${ }^{\mathrm{a}}$ Softening temperature, defined as the temperature at which the stirrer starts to rotate.

${ }^{\mathrm{b}}$ Maximum fluidity temperature.

${ }^{\mathrm{c}}$ Resolidification temperature, defined as the temperature at which the stirrer stops.

${ }^{\mathrm{d}}$ Plastic range.

${ }^{\mathrm{e}}$ Maximum fluidity expressed in dial divisions per minute (ddpm). 
Table 3. Parameters derived from thermogravimetric analysis (at $3{ }^{\circ} \mathrm{C} / \mathrm{min}$ ) of additives (T, CTS), fresh (LV, HV) and oxidized (LVOB, LVO, HVOB, HVO) coals and their mixtures with 2 wt. $\%$ of additives.

\begin{tabular}{|c|c|c|c|c|c|c|c|c|c|}
\hline & $\begin{array}{l}\mathrm{T}_{5 \%} \\
\left({ }^{\circ} \mathrm{C}\right)^{\mathrm{a}}\end{array}$ & $\begin{array}{l}\mathrm{T}_{95 \%} \\
\left({ }^{\circ} \mathrm{C}\right)^{\mathrm{b}}\end{array}$ & Tf-Ti & $\begin{array}{l}\text { VM400 } \\
(\%)^{\mathrm{c}}\end{array}$ & $\begin{array}{l}\text { VM400- } \\
500(\%)^{\mathrm{c}}\end{array}$ & $\begin{array}{l}\text { VM500- } \\
750(\%)^{\mathrm{c}}\end{array}$ & $\begin{array}{l}\text { DTGmax } \\
(\% / \mathrm{min})^{\mathrm{d}}\end{array}$ & $\begin{array}{l}\text { Tmax } \\
\left({ }^{\circ} \mathrm{C}\right)^{\mathrm{e}}\end{array}$ & $\begin{array}{l}\mathrm{CY} \\
(\%)^{\mathrm{f}}\end{array}$ \\
\hline $\mathrm{T}$ & 135 & 491 & 356 & 87.0 & 8.4 & 1.9 & 0.83 & 199 & 34.0 \\
\hline CTS & 139 & 468 & 329 & 87.9 & 8.6 & 2.3 & 0.80 & 201 & 42.3 \\
\hline LV & 378 & 831 & 453 & 7.5 & 50.8 & 32.9 & 0.50 & 472 & 78.6 \\
\hline LVOB & 375 & 847 & 472 & 7.9 & 49.0 & 33.7 & 0.48 & 474 & 78.4 \\
\hline LVO & 367 & 840 & 473 & 8.4 & 47.3 & 34.8 & 0.45 & 475 & 78.8 \\
\hline LVO2T & 285 & 847 & 562 & 13.0 & 45.2 & 32.4 & 0.46 & 472 & 77.0 \\
\hline LVO2CTS & 229 & 840 & 611 & 16.2 & 43.4 & 31.4 & 0.45 & 474 & 76.7 \\
\hline $\mathrm{HV}$ & 336 & 797 & 461 & 14.6 & 56.0 & 22.6 & 0.83 & 451 & 67.8 \\
\hline HVOB & 333 & 764 & 431 & 15.6 & 55.6 & 23.3 & 0.75 & 450 & 69.9 \\
\hline HVO & 317 & 783 & 466 & 16.6 & 53.8 & 23.6 & 0.74 & 446 & 69.5 \\
\hline HVO2T & 297 & 827 & 475 & 17.7 & 52.9 & 22.8 & 0.75 & 449 & 68.4 \\
\hline HVO2CTS & 310 & 769 & 458 & 17.4 & 53.9 & 22.9 & 0.74 & 449 & 69.5 \\
\hline
\end{tabular}

a Temperature at $5 \%$ conversion.

b Temperature at $95 \%$ conversion.

c Volatile matter evolved up to a specific temperature $(\mathrm{T})$ or in a specific temperature range and normalized to $100 \%$.

$\mathrm{d}$ Maximum rate of volatile matter evolution.

e Temperature of maximum volatile matter released.

f Coke yield at $1000^{\circ} \mathrm{C}$. 
Table 4. Coking pressure data and expansion/contraction of fresh (LV, HV), oxidized coals (LVOB, LVO, HVOB, HVO) and mixtures with 2 wt. \% of additives.

\begin{tabular}{lccc}
\hline & $\begin{array}{c}\text { Koppers-INCAR tests } \\
\text { Contraction } \\
(\mathrm{mm})\end{array}$ & $\begin{array}{c}\text { Expansion } \\
(\mathrm{mm})\end{array}$ & $\begin{array}{c}\text { MOW17 } \\
\mathrm{P}(\mathrm{kPa})\end{array}$ \\
\hline LV & -8.5 & +0.5 & 19 \\
LVOB & -6.5 & +1.5 & 32 \\
LVO & -4.5 & +4.0 & 35 \\
LVO2T & -3.5 & +5.5 & 44 \\
LVO2CTS & -6.5 & +3.0 & 38 \\
\hline HV & -20 & 0 & 4 \\
HVOB & -23 & 0 & 4 \\
HVO & -22 & 0 & 4 \\
HVO2T & -17 & 0 & 3 \\
\hline
\end{tabular}


Table 5. Quality parameters of cokes produced from fresh (LV, HV), oxidized coals (LVOB, LVO, HVOB, HVO) and mixtures with 2 wt. \% of additives.

\begin{tabular}{lccccccccc}
\hline Coke & LV & LVOB & LVO & LVO2T & LVO2CTS & HV & HVOB & HVO & HVO2T \\
\hline CRI (\%) & 18 & 17 & 18 & 18 & 19 & 27 & 26 & 31 & 27 \\
CSR (\%) & 70 & 70 & 70 & 71 & 71 & 54 & 54 & 46 & 50 \\
DI150/15 & 81.4 & 76.0 & 75.9 & 79.0 & 78.5 & 79.5 & 72.7 & 72.5 & 74.1 \\
DI 150/5 & 12.1 & 17.9 & 14.0 & 12.0 & 14.5 & 13.8 & 17.6 & 18.7 & 17.2 \\
\hline
\end{tabular}




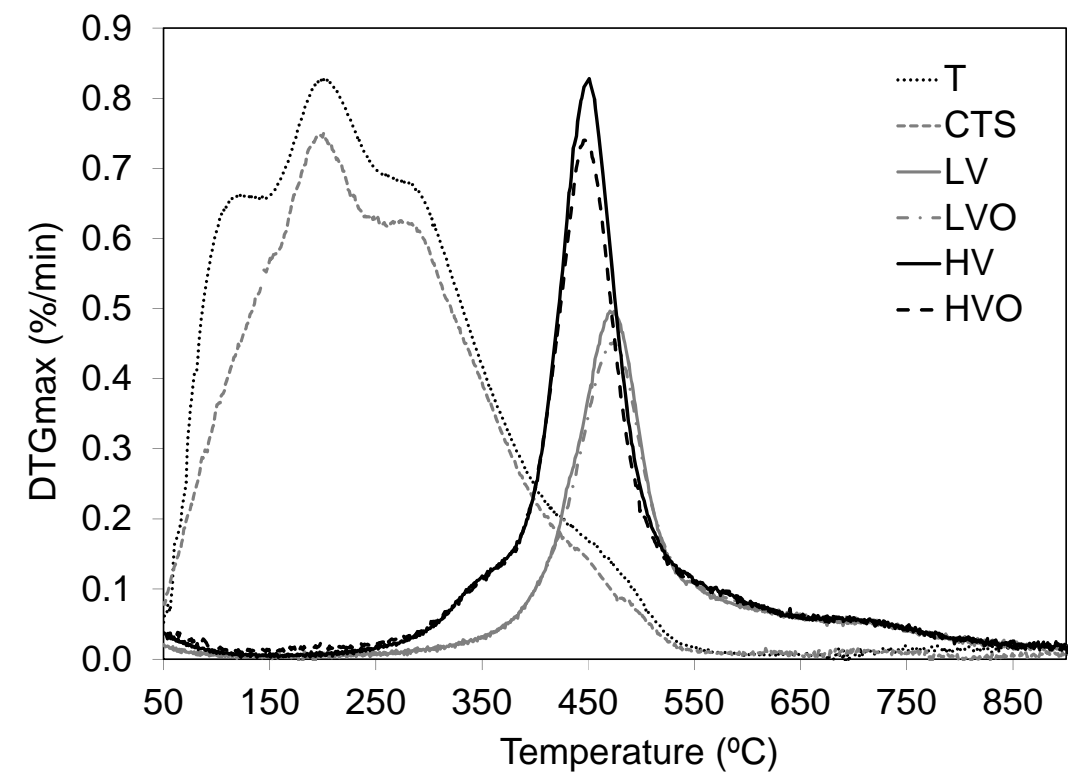

Figure 1. DTG curves of the coals (LV, HV), the oxidized coals (HVO, LVO) and the additives (CT, CTS). 


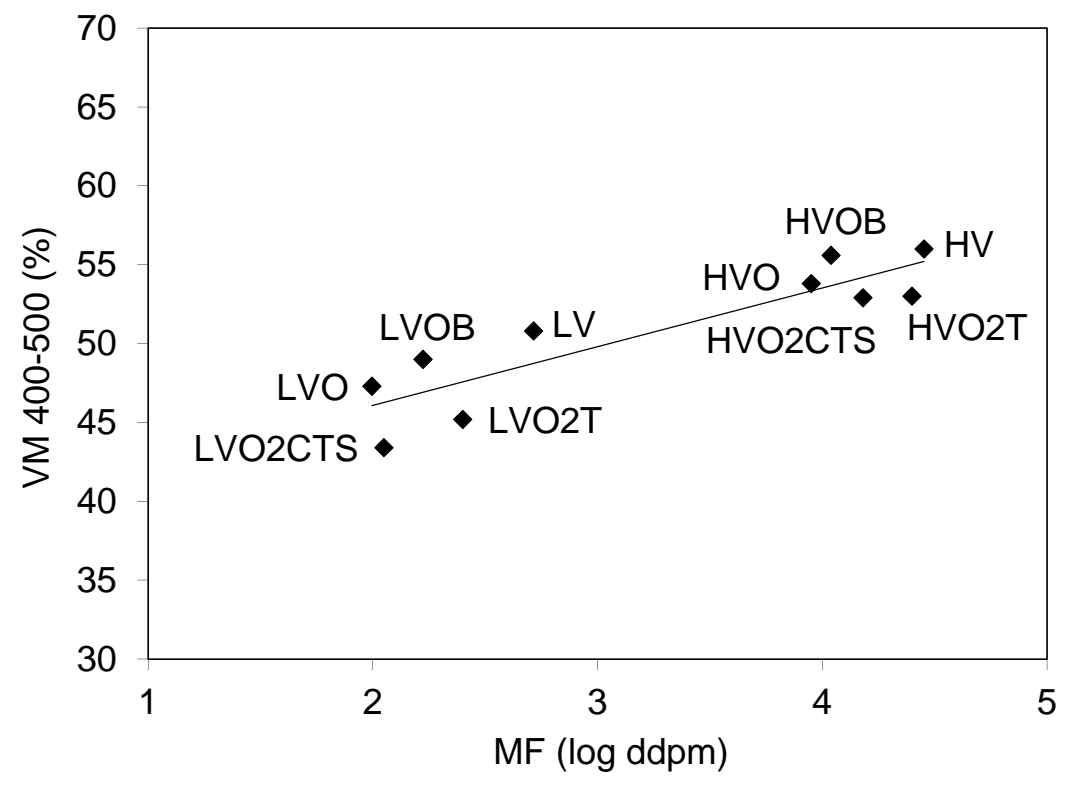

Figure 2. Relationship between the Gieseler maximum fluidity and the volatile matter evolved between 400 and $500{ }^{\circ} \mathrm{C}$. 

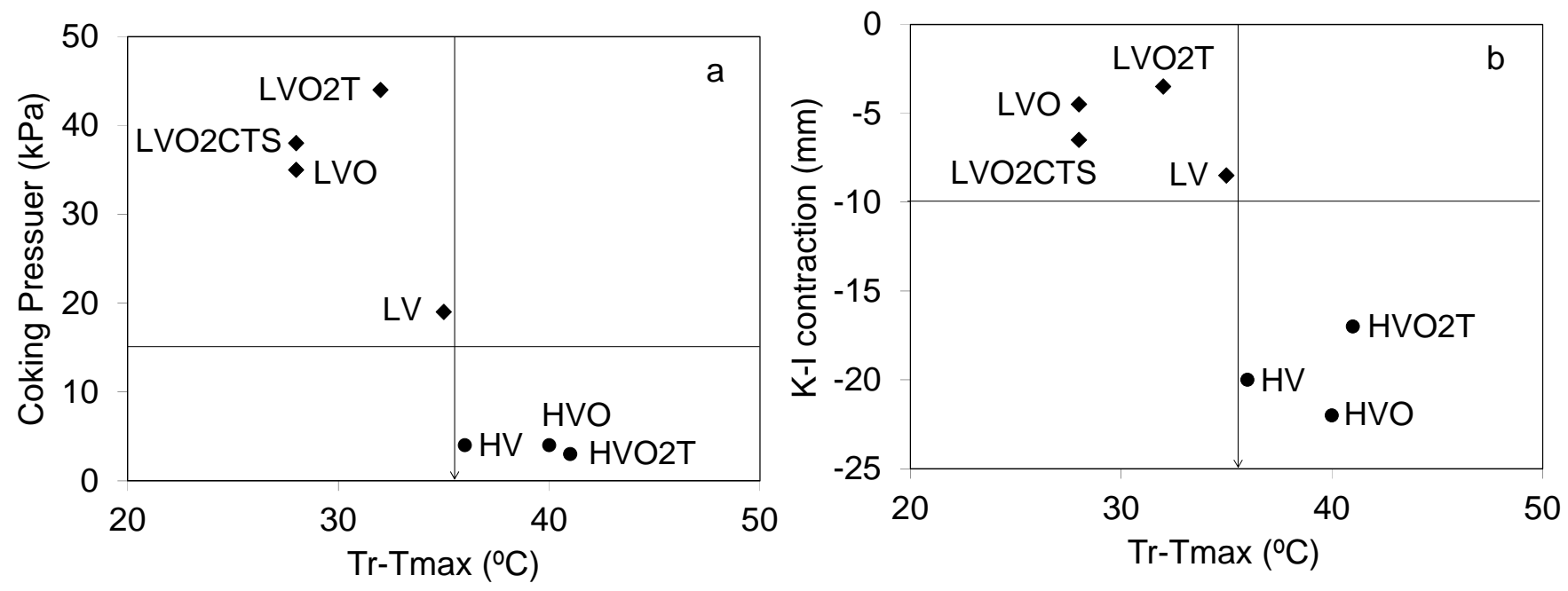

Figure 3. Relationship of the difference between the resolidification temperature and the temperature of maximum rate of volatile matter evolution to (a) coking pressure and (b) semicoke contraction. 


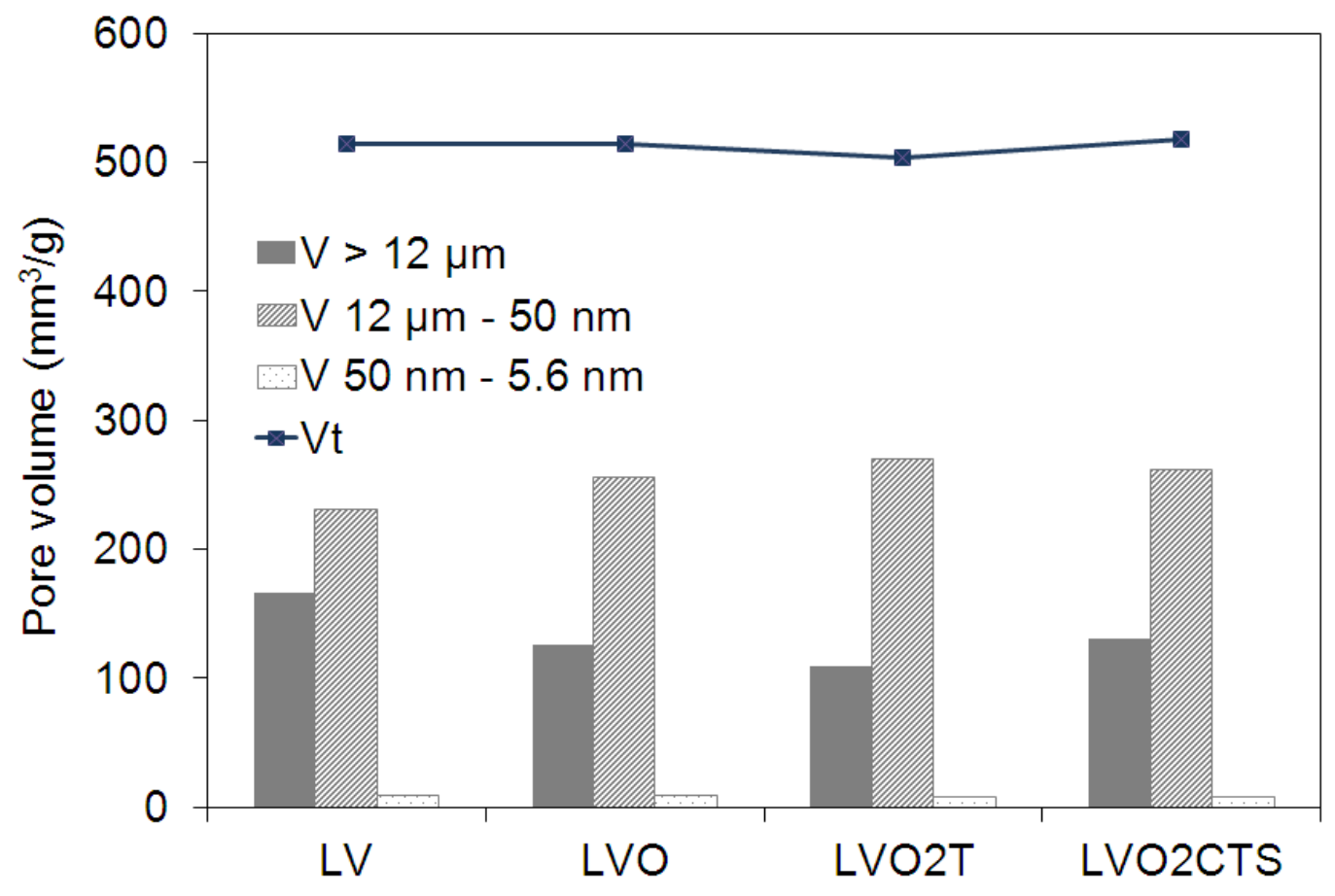

Figure 4. Pore size distribution of the semicokes obtained at $575{ }^{\circ} \mathrm{C}$. 


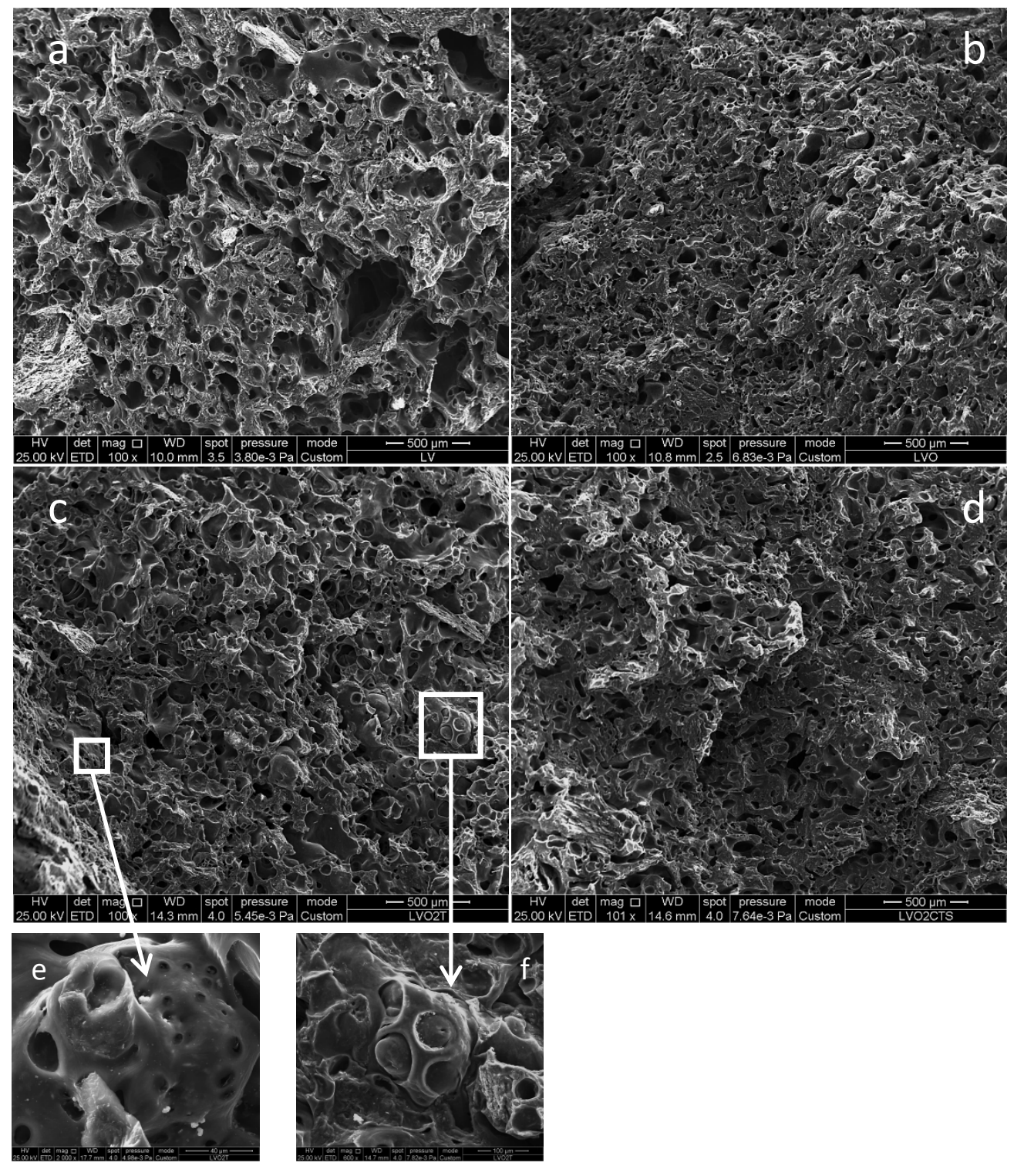

Figure 5. SEM images of semicokes obtained from (a) LV, (b) LVO, (c) LVO2T, (d) LVO2CTS. (e) and (f) show in a higher magnification the selected part marked with squares in the LVO2T image. 

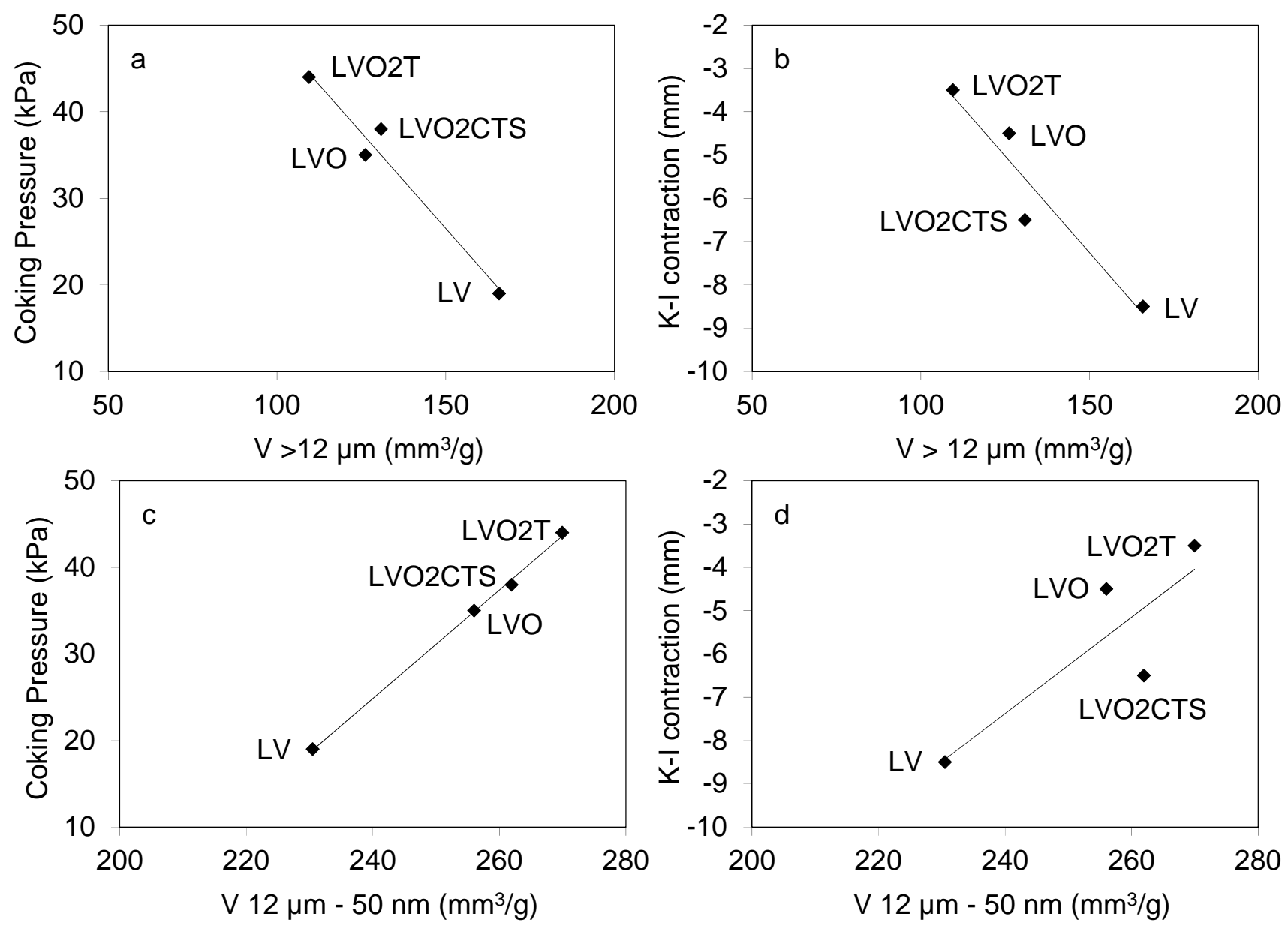

Figure 6. Relationship between the volume of pores $>12 \mu \mathrm{m}$ and coking pressure (a), K-I contraction (b) and volume of pores $12 \mu \mathrm{m}-50 \mathrm{~nm}$ and coking pressure (c), K-I contraction (d). 